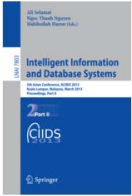




\title{
Infrastructure vs. Access Competition in NGNs
}

\author{
João Paulo Ribeiro Pereira \\ School of Technology and Management, Polytechnic Institute of Bragança (IPB), Portugal \\ jprpaipb.pt
}

\begin{abstract}
With the introduction of NGNs, operators need to upgrade their access networks because in several cases, existing access networks can no longer meet increasing customer expectations. Evolving consumer expectations will require changes to the existing access network - next generation access. However, existing technologies faces some difficulties and are not ready for large-scale roll-out yet. For example, in the case of DSL technologies, the great majority of operators with copper networks are improving their networks, making investments to deploy fiber optics closer to customers and offering higher-speed access, which is required for new emerging services (reducing the distance between fiber and the users.). The entry of new competitors can be based on the resale of services from the incumbent, on building up their own infrastructures, on renting unbundled infrastructure from incumbents, or, on the combination of the above elements. Then, is important create the right incentive for operators to make an efficient build/buy choice and define the appropriate pricing principles.
\end{abstract}

Keywords: NGNs, Broadband Access Networks, Telecommunication network operators, policy and regulation.

\section{Introduction}

The advent of NGN (new network technologies, access infrastructures, and even services) has changed the concept of telecommunication networks and has profound implications for operators and regulators. The definition of policies and regulations for competition in the access networks constitute one of the most debated issues in telecommunications today. The regulation of telecommunications networks and services is seen as a necessary requirement in most countries to meet government objectives and to ensure public interest. Regulation is fundamental to generate positive welfare effects where markets alone would not tend to perfect competition.

But, as referred by [1], the major problem is how to measure these welfare effects, as they can occur as consumer surplus, producer surplus, societal gains (e.g., increased tax income, better working conditions, etc.). Their empirical study uses price situation to examine the welfare effects measured by the state of competition. They assumed that the increase of competition reduces prices in the market and that competition can also increase consumer welfare without reducing prices (achieved by 
innovation). Public policies should promote an efficient investment and competition in all markets (see fig. 1).

The two main economic reasons that have been used to justify interventions in access networks are the beliefs that access networks constitute a natural monopoly for which competition is not feasible in principle and that regulation is, therefore, necessary to control monopoly power and to achieve universal service in which all (or most) users have the opportunity to affordably access the services of the network. The challenge of telecom operators to provide a profitable deployment of broadband services depends if is a high or a low competition area. In areas with high competition already exists competition between broadband network operators, and the main question is know the market share of all intervenient. However, in low competition areas high investments cost must be incurred to promote broadband. [2] argued that national or regional policy concerns can also affect NGA roll out. Without some type of intervention, there is the risk for a new digital divide, with urban customers on short loops being able to receive IPTV/multi-media services and HDTV while those in rural areas might not be able to receive such services. Therefore, the access network poses serious challenges to the regulator [3].

The question then becomes whether it is more important to stimulate investment or to ensure competition. Investment in network quality is important for consumers because it provides access to both better quality and speed to services, such as Web browsing and email, and services that require more bandwidth, such as video. Investment in network quality also improves the service value for consumers and attracts new consumers to the market. Therefore, there are two major options for access regulation [2]: temporary or permanent deregulation (i.e., the removal of sector-specific rules and regulations) or mandated access (i.e., the obligation to grant access to bottleneck facilities at a regulated price and quality). Deregulation increases investment incentives, as it overcomes the "truncating problem" and allows above-normal profits. However, in the absence of alternative infrastructures or in areas of low population density under limited competition or the threat of entry into the upstream market, an integrated incumbent might leverage its market power to competitive downstream segments.

For NRAs, one request of decisive importance is if they must foster service-based competition in the first phase of liberalization or to focus on infrastructure-based competition. This decision (infrastructure or service-based) would lead to lower prices, more differentiated and innovative products and improved services for consumers. When access is available at different levels of the incumbent's network, new entrants will be able invest in the infrastructure gradually as sufficient economies of scale became achievable - This concept is the ladder of infrastructure competition. This concept defends that new entrants (or access seekers) may enter the market offering broadband access by reselling the wholesale services of the incumbent operator (requires least investment) where they only cover minor elements of the value chain (Figure 2). When the number of customer grows and financial means become available, the operator move on to higher rungs of the ladder [1, 4]. Next, new entrants need to building their own infrastructure and acquiring only the residual infrastructure from the incumbent's wholesale department. This includes a move for the operators from service to infrastructure-based competition. 
The migration to NGAN has raised a range of issues related to building wiring and infrastructure sharing. The deployment strategies for operators and entrants are completely different. In addition, parameters, such as existent infrastructure, geographical characteristics, infrastructure renting costs, and consumer willingness to pay, influence the definition of the strategy. So, telecommunication operators can select among a set of deployment strategies that are characterized by path dependency and diminishing usage of the legacy copper loop. The range of the selection space is based upon how much of the copper they use and, consequently, how far toward the customer they deploy new fiber. In the final step, operators replace all of the copper with FTTH. Within that scenario, FTTH can be implemented as either active Ethernet or passive optical networks, although most incumbent operators tend to select PON.

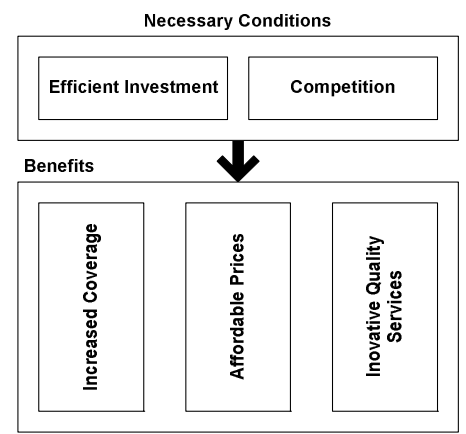

Fig. 1. Policies effects [5]

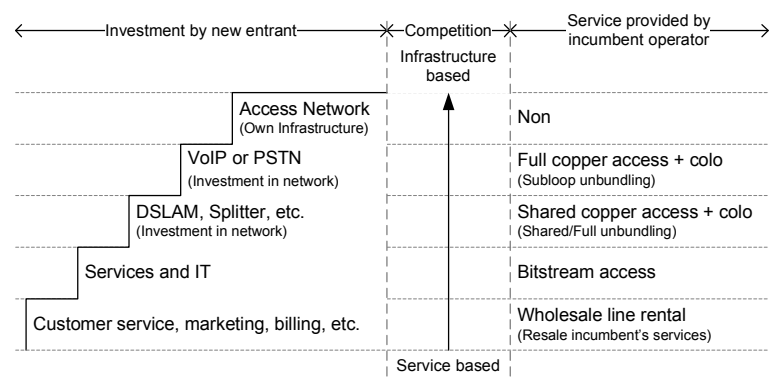

Fig. 2. Ladder of investment $[6,7]$

The strategy of a new entrant in an access network that does not have an infrastructure can be one of the following three alternatives (Fig. 3): (1) Renting infrastructure (i.e. conduit, cable, equipment, ...) from other operators and offering only services (infrastructure sharing); (2) Deploying a new infrastructure; or (3) Not participating at all. 
Deployment strategies for incumbent operators

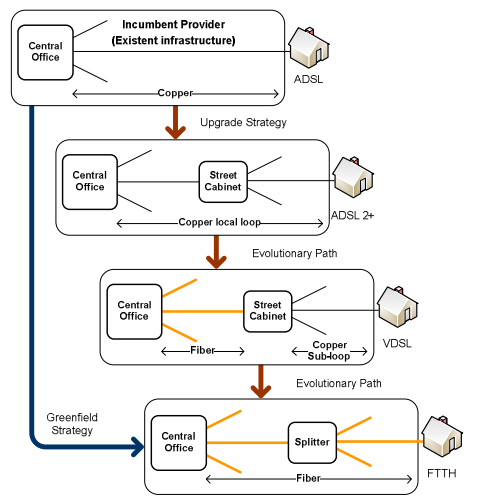

Deployment strategies for entrants

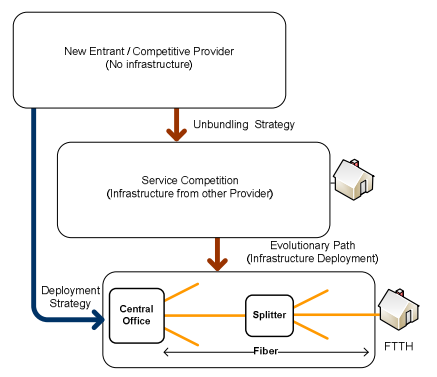

Fig. 3. Deployment strategies for incumbent operators and new entrants $[8,9]$

Regulators must decide whether to promote competition on the basis of a single infrastructure with regulated access (service competition) or to encourage the build-up of competing, parallel infrastructures (infrastructure competition) [10]. Then, is important create the right incentive for operators to make an efficient build/buy choice and define the appropriate pricing principles. To obtain economic efficiency, a regulator should [6]: (1) Encourage the use of existing infrastructure of the incumbent operator where this is economically desirable, avoiding inefficient duplication of infrastructure costs by new entrants (incentive to buy); and (2) Encourage investment in new infrastructure where this is economically justified by (a) new entrants investing in competing infrastructure, and (b) the incumbent operator upgrading and expanding its networks (incentive to build).

In this context, the cost models are fundamental in the determination of the access price that can be used by regulators in the definition of wholesale prices.

\section{Infrastructure-Based Competition}

European Commission argues that infrastructure-based competition is the best and fastest way for broadband development. The arguments are that infrastructure based competition provides efficiency incentives to operators, reduces prices, increase penetration, stimulates innovation, etc. The empirical study deployed by [1] concludes that prices are lower and penetration rates are higher in those countries with predominantly infrastructure-based competition. However, broadband development and infrastructure-based competition has higher costs (the cost of laying out these infrastructures and operation inefficiencies of duplicating/redundant infrastructures).

The entry of competitors in the infrastructure-based market is dependent on the cost of the alternative technology. An efficient market entry is based in retail rates and access prices (reflect the cost of using the incumbent's network). So, infrastructurebased entrants can offer differentiated services at equal (or lower) costs (and thereby increase consumer welfare), when the cost of providing broadband access by an alternative network is lower (or equal) than the incumbent's cost of providing broadband access services [11]. The share of LLU is increasing in favor of bitstream 
access. This could be understood that the competition in the lowest possible layers allows more degrees of freedom to differentiate. However, competition in this layers could not be not technically feasible (e.g., constraints in ducts or sewers implies that fiber cables cannot be installed) or economically feasible (e.g., in rural areas where the business case for FTTH isn't attractive).

\subsection{Build or Upgrade Infrastructure}

In NGNs, infrastructure-based entry into the local loop can occur in two ways: by constructing new networks (greenfield approach) or by upgrading existing networks [12]. Upgrading existing networks can be driven by the increase in number of subscribers, the introduction of new services, the conversion to broadband access infrastructure, or modernization of existing access solutions using different access technology than previously installed.

With the exception of wireless networks, which constitute a low-cost investment, the construction of parallel infrastructures that are similar in costs and capabilities remains unlikely in NGNs. However, providers can enter the market successfully by deploying a superior network with lower costs and/or higher quality alongside an existing infrastructure. In many European countries, next generation access will most commonly use FTTCabinet architecture. The replacement of the traditional copperbased access with new fiber-based access potentially both enables a significant increase in the capacity and ability to support new services and lowers operating and maintenance costs as compared to copper [13]. However, the initial cost of deploying it is substantial. Alternative operators require access to civil engineering. For an operator rolling out a fiber optical network, access to existing civil engineering changes the economic equation considerably. Therefore, all operators are not on equal footing. Alternative operators have begun to introduce optical fiber only in large markets. In addition, incumbent operators are rolling out optical fiber in their civil engineering ducts, which they inherited from the former monopoly.

NGA fiber rollout requires substantial investment, and incumbents are better positioned than new entrants to make these investments on a large scale because of the associated lower costs of infrastructure usage, investment savings by dismantling MDFs, better use of passive infrastructure, and larger subscriber base [5]. The technologies used by most, but not all, network operators are FTTC/VDSL and FTTH/B (P2P and PON). The FTTC/VDSL solution uses copper access line from the network operator's MDF in the CO, to the street cabinet is replaced by a fiber optic line. In FTTH PtP networks, the copper access line from the network operator's CO to the end user's residence is replaced by a fiber optic line that is effectively dedicated to a single customer. In FTTH (PON) the copper access line from the network operator's $\mathrm{CO}$ to the end user's residence is replaced by a fiber optic line.

\section{Service-Based Competition}

The large investments required to build/upgrade a network capable of supporting broadband access services could be a barrier to enter into the market. [14] argues that service-based competition is only viable with regulatory intervention in the market. National Regulatory Authorities (NRA) intervention is important for regulation costly 
and to offer the right incentives for innovation and cost-minimization. For that, the regulators need correct information on technologies, costs, market, etc.

By NRA definition, incumbent networks were opened to facilitate competition. With this policy, new entrants could rent the elements of the incumbents' networks with stipulated prices, which enabled competitors to utilize last-mile incumbent network facilities at cost-oriented prices under the following arrangements [15-16]: Bitstream access, Local loop unbundling (LLU), and shared access. The report from the ERG [7] identified LLU and wholesale broadband access (Bitstream) as key areas where harmonization might significantly help deliver benefits of a single electronic communications market.

Mandated access to the bitstream or the unbundled line reduces uncertainty and protects competition in the downstream market, although the effects on investment depend upon the allowed margin. Further, regulated access to cable ducts can help competitors to deploy, restructure, or upgrade their access infrastructure. In NGNs, physical unbundling becomes increasingly difficult with the rollout of FTTH deployments, as current points of interconnection, such as the MDF or the street cabinets, become obsolete and are phased out. In the case of FTTH, investments by competitors to interconnect physical access points in the local loop might ultimately be stranded.

\section{Wholesale Access Services}

Some operators have decided to share their networks under several options in order to reduce their CAPEX and OPEX (e.g., ducts, fiber, site sharing, etc.). For new entrants, is possible without higher investments in local loops, reduce the risks of entry, which leads in the long run to more investment in alternative access network infrastructures [17]. Table 1 presents the types of wholesale access.

Table 1. Types of wholesale access (Summary)

\begin{tabular}{|l|l|}
\hline Type & Description \\
\hline $\begin{array}{l}\text { Local loop } \\
\text { unbundling } \\
\text { (LLU) or } \\
\text { unbundled } \\
\text { local loop } \\
\text { (ULL) }\end{array}$ & $\begin{array}{l}\text { Is the recommendation by which incumbent operators are obliged to open } \\
\text { their copper-based line access networks other operators (new entrants). In the } \\
\text { use. This access method uses the incumbent's copper access line from the CO } \\
\text { to the customer premises, but the LLU operator provides its own electronics at } \\
\text { the CO to enable the local loop for broadband [18]. }\end{array}$ \\
\hline $\begin{array}{l}\text { Shared } \\
\text { access } \\
\text { lines }\end{array}$ & $\begin{array}{l}\text { Shared access lines supplied by the incumbent to other operators (new en- } \\
\text { trants). A fundamental feature of shared access is that it is provided over a } \\
\text { subset of the full frequency spectrum of the line (copper, coax, fiber, ...). } \\
\text { Cable is a separate access network generally not owned by the incumbent } \\
\text { operator, except in Portugal [189]. The cost of the line is shared between the } \\
\text { shared access services. }\end{array}$ \\
\hline $\begin{array}{l}\text { Bitstream } \\
\text { access }\end{array}$ & $\begin{array}{l}\text { It refers to the situation where the incumbent installs a high-speed access link } \\
\text { to the customer premises, and makes this access link available to new } \\
\text { entrants, to enable them to provide high-speed services to customers [16]. } \\
\text { Bitstream access is a wholesale access product which allows alternative } \\
\text { operators to offer BB Internet access to the final costumer without having an } \\
\text { own access line [19]. }\end{array}$ \\
\hline
\end{tabular}




\subsection{Wholesale Pricing}

One of the variables that can influence the level of competitiveness is the access price definition. Access prices are essentially the wholesale prices that network owners (normally incumbent operators) charge to the other operators (competitors) for access to infrastructure or services provided by the incumbent network infrastructure.

Where the incumbent's network is opened to competitors at more than one level (e.g. LLU, wholesale broadband access and wholesale line rental), regulators have to project correctly the relative prices of the different options in relation to one another and in relation to the retail prices prevailing in the market [20]. An incorrect definition of the access price can affect the level of competition and welfare loss. For example, a lower price will reduce the incentive of the infrastructure owners to invest in the infrastructure because they do not receive an adequate return on their investment. Further, a higher price will reduce the capacity of competitors to compete - a low price for access encourages use but discourages investment and vice versa.

To be able to make the ladder of investment operational it is necessary that prices in wholesale markets are consistent for the different products [1]. The definition of access pricing is critical when network access is a vital input to deploying services to end consumers. In a market where the network owner also operates at the retail market, competing with other firms the access pricing definition is a key question and is frequently considered to be an economic regulation problem. To assure a legal competition, the NRAs have to control the price scheme of the wholesale regimen for the bitstream access services or even determine the upper price levels. The EU has to provide the directives to promote homogeneity in the price regulation scheme.

Without access price regulation, network owners may be tempted to exercise market power and block access to the network. On the other hand, significant control of the access price can discourage the realization of investments in the quality of the network. Consequently, a lower access price can result in inefficient input, whereas a higher access price can lead to inefficient investments with the objective of reducing dependence upon the incumbent operator. Then, the regulator can use the access pricing definition to influence the decisions of new firms' inputs in the retail segment.

In Portugal, a recent European Commission report [21] shows that LLU prices have not been modified and continue to be just above the EU average. The monthly average total cost was $€ 10.05$ for full unbundling and $€ 3.57$ for shared access in October 2010 (compared to EU averages of $€ 9.61$ and $€ 3.29$ respectively).

\subsection{Wholesale Access Market}

For new entrants, LLU (fully unbundled lines and shared access) is the main wholesale access with $76.2 \%$ (in January 2011) of DSL lines, up from $65.2 \%$ in July 2008 (Source: EC). New entrants' use of bitstream access for local loop unbundling in the provision of broadband services went up by 1 percentage point since July 2008 . 
The share of resale, which represents a type of access for low-investment intensive new entrants, has shrunk by $7.6 \%$ during the last year. Previous figure shows the evolution since 2007 of DSL lines by type of access.

Table 2 presents the types of access of the new entrants for Portugal and EU. In Portugal, LLU continues to be the preferred wholesale option for alternative operators, with $83.4 \%$ (2010) of lines. However, the number of fully unbundled lines (shared access is not used) for the provision of broadband services has decreased from 269.066 in January 2010 to 229.098 in January 2011 [21]. Table 2 shows that there is a bigger difference in the use of shared access between Portugal and EU average.

Table 2. New entrants` DSL lines by type of access (EU and Portugal), 2009/11 (Source: EC)

\begin{tabular}{|l|c|c|c|c|c|}
\hline \multirow{2}{*}{\multicolumn{1}{c|}{$\begin{array}{c}\text { Type of } \\
\text { access }\end{array}$}} & \multicolumn{3}{|c|}{ EU level } & \multicolumn{2}{c|}{ Portugal } \\
\cline { 2 - 6 } & 2009 & 2010 & Jan. 2011 & 2009 & 2010 \\
\hline Own network & $0,9 \%$ & $0,9 \%$ & $1.2 \%$ & $0,0 \%$ & $0,0 \%$ \\
\hline Full ULL & $54,4 \%$ & $61,5 \%$ & $63.9 \%$ & $86,6 \%$ & $83,4 \%$ \\
\hline Shared access & $16,9 \%$ & $13,3 \%$ & $12.3 \%$ & $0,0 \%$ & $0,0 \%$ \\
\hline Bitstream & $17,0 \%$ & $15,4 \%$ & $14.5 \%$ & $13,4 \%$ & $16,4 \%$ \\
\hline Resale & $10,7 \%$ & $8,9 \%$ & $8.1 \%$ & $0,0 \%$ & $0,2 \%$ \\
\hline
\end{tabular}

In Portugal, competition is strong in urban areas, where unbundling is highly developed, but in rural areas, incumbent operator remains largely dominant. In 2009, the $\%$ of DSL connections was different by type of provider: a) Urban area - ULL:41,0\%, Bitstream/Resale:4,0\% and Incumbent retail:55,0\%; b) Rural area - ULL: 8,5\%, Bitstream / Resale: 5,5\% and Incumbent retail: 86,0\%. [6] defends that an effective and sustainable infrastructure competition is superior to service competition, as it allows for head-to-head competition between operators and requires a minimal need for regulatory intervention with competitors not being reliant on the incumbent infrastructure. So, operators, especially new entrants, will have a choice as to whether they should invest in their own infrastructure (i.e. build) in order to provide services to end-users, or to seek access (buy) from an existing provider (normally the incumbent).

\section{Conclusion}

The analysis of the broadband market suggests that where infrastructure competition exists, as in DSL and wireless broadband, service providers will more aggressively price their offerings, driving down the access price for consumers. However, in the case of limited infrastructure competition, broadband access price remains high for consumers. Infrastructure competition between DSL, Cable and wireless solution, had a significant and positive impact on the broadband penetration. We verify that opening access networks (and network elements) to competitive forces increases investment and the speed of development. Despite increasing competition, 
incumbents are maintaining their dominant position. More than $60 \%$ of all broadband subscriptions make use of incumbent's broadband access infrastructure. In countries/regions where alternative technological platforms are not developed, the deployment of the DSL technology depends on the use of the networks infrastructures that are propriety of incumbent operators. To facilitate market entry of new competitors and develop competition in the access market, the regulatory authorities are focused on unbundled access to the local loop (fully unbundled local loop and shared access to the local loop) and on different forms of network access (bitstream and resale).

\section{References}

1. Kittl, J., Lundborg, M., Ruhle, E.-O.: Infrastructure-based versus service-based competition in telecommunications. Communications \& Strategies, 67 (2006)

2. Collins, H.: Next Generation Networks - Creating a Dedicated Cost Model. InterConnect Communications Ltd., United Kingdom (2009)

3. Marcus, J.S., Elixmann, D.: Regulatory Approaches to NGNs: An International Comparison. Communications \& Strategies 69, 21 (2008)

4. Xavier, P.: Geographically Segmented Regulation for Telecommunications. In: OECD 2010 (2010)

5. Oliveira, A.: Next Generation Access Networks: A key factor of development. In: NGON Seminar - ISCTE, Lisbon, pp. 1-33 (2009)

6. Andersen Int., Pricing Shared Access in Sweden, Post- of Telestyrelsen., Sweden (2004)

7. ERG, Report on ERG Best Practices on Regulatory Regimes in Wholesale Unbundled Access and Bitstream Access. European Regulators Group (2008)

8. Pereira, J.P., Ferreira, P.: Game Theoretic Modeling of NGANs: Impact of retail and wholesale services price variation. Journal of Communications (2012)

9. Pereira, J.P., Ferreira, P.: Infrastructure Sharing as an Opportunity to Promote Competition in Local Access Networks. Journal of Computer Networks and Communications, 11 (2012)

10. Höffler, F.: Cost and benefits from infrastructure competition. Estimating welfare effects from BB access competition. Telecommunications Policy 31, 401-418 (2007)

11. Vanberg, M.A.: Competition in the German BB Access Market. ZEW Mannheim (2004)

12. Kirsch, F., Hirschhausen, C.V.: Regulation of Next Generation Networks: Structural Separation, Access Regulation, or no Regulation at all? In: NFRA, Rotterdam, The Netherlands, pp. 1-8 (2008)

13. Jaag, C., Lutzenberger, M.: Approaches to FTTH-Regulation: An International Comparison. In: Second Annual Conference on Competition and Regulation in Network Industries, Brussels, Belgium, p. 23 (2009)

14. Laffont, J.-J., Tirole, J.: Competition in Telecommunications. The MIT Press, Cambridge (2001)

15. Marcus, J.S., Elixmann, D., Wernick, C.: Next Generation Networks (NGNs). European Parliament, Brussels (2009)

16. European Commission, Electronic Communications Market Indicators. EC (2011)

17. Cas, J.: Alternative local loop technologies - impact on regulation and competition. Presented at the ITS European Conference, Turin, Italy (1999) 
18. Cadman, R.: Inconsistent Regulation, Market Structure and Broadband Adoption in the EU: a Dynamic Model. Strategy \& Policy Consultants Network Ltd and ESRC Centre for Competition Policy (2008)

19. Cardona, M., Schwarz, A., Yurtoglu, B., Zulehner, C.: Demand estimation and market definition for broadband Internet services. Journal of Regulatory Economics 35, 70-95 (2009)

20. OECD, Geographically Segmented Regulation for Telecommunications. OECD Digital Economy Papers 173, 78 (2010)

21. European Commission, Main market developments. European Commission (2011) 